\title{
REVIEW
}

\section{Clinical review: Extracorporeal membrane oxygenation}

\author{
Luciano Gattinoni',2*, Eleonora Carlesso ${ }^{2}$ and Thomas Langer ${ }^{2}$
}

\begin{abstract}
The H1N1 flu pandemic led to a wider use of extracorporeal membrane oxygenation (ECMO), proving its power in hypoxemic emergencies. The results obtained during this pandemic, more than any randomized trial, led to the worldwide acceptance of the use of membrane lungs. Moreover, as centers that applied this technique as rescue therapy for refractory hypoxemia recognized its strength and limited technical challenges, the indications for ECMO have recently been extended. Indications for venovenous ECMO currently include respiratory support as a bridge to lung transplantation, correction of lung hyperinflation during chronic obstructive pulmonary disease exacerbation and respiratory support in patients with the acute respiratory distress syndrome, possibly also without mechanical ventilation. The current enthusiasm for ECMO in its various aspects should not, however, obscure the consideration of the potential complications associated with this life-saving technique, primarily brain hemorrhage
\end{abstract}

\section{Introduction}

Extracorporeal membrane oxygenation (ECMO) is a temporary artificial extracorporeal support of the respiratory system and/or cardiac system used for the treatment of cardiopulmonary failure refractory to conventional therapies. More than 1,000 papers on ECMO published between January 2009 and May 2011 (PubMed search) clearly indicate a renewed interest in the technique, initially triggered by the CESAR trial publication [1] and the recent H1N1 flu pandemic. Indeed, during the pandemic the number of patients with acute

\footnotetext{
${ }^{*}$ Correspondence: gattinon@policlinico.mi.it

2Dipartimento di Anestesiologia, Terapia Intensiva e Scienze Dermatologiche, Fondazione IRCCS Ca' Granda Ospedale Maggiore Policlinico di Milano, Università degli Studi, Via Francesco Sforza 35, 20122 Milano, Italy

Full list of author information is available at the end of the article
}

respiratory distress syndrome (ARDS) who were not safely treatable with current clinical settings of mechanical ventilation $(6$ to $8 \mathrm{ml} / \mathrm{kg}$ tidal volume normalized on ideal body weight and plateau pressure lower than 30 to $35 \mathrm{cmH}_{2} \mathrm{O}$ ) and who therefore received extracorporeal respiratory support appeared to be greatly increased. After providing a brief background and some technical notes, we will review the most important and recent findings related to the technique, its application and future applications.

Long-term ECMO, as support for severe respiratory failure, was first successfully used in 1972 in an adult patient with post-traumatic respiratory failure [2]. A few years later, at the University of California, Bartlett and colleagues successfully treated a newborn with ECMO [3]. The enthusiasm for this new technique led to a randomized trial sponsored by the National Institutes of Health that compared venous-arterial ECMO with conventional mechanical respiratory support in severe ARDS [4]. After randomization of 90 patients the trial was stopped for futility because the mortality in both groups was around $90 \%$. However, one should note that the greatest concern for mechanical ventilation, at that time, was the high fraction of inspired oxygen and not the high ventilator pressure/volume; that is, nonphysiological stress and strain. In this ECMO trial, therefore, the only difference in mechanical ventilation settings between treatment and control patients was a lower $\mathrm{FiO}_{2}$ in the group that received the extracorporeal support. Moreover, the ECMO technology at these times was very primitive, with consistent risks for the patients due to high priming volumes of the extracorporeal circuits and elevated bleeding risks associated with systemic anticoagulation. The limitations of this trial passed mostly unrecognized, however, and the discouraging results therefore led to the ECMO technique being abandoned worldwide.

During the same years, Kolobow was developing a new membrane lung optimized for carbon dioxide $\left(\mathrm{CO}_{2}\right)$ removal as a possible application in patients with chronic obstructive pulmonary disease. While testing this new device in spontaneously breathing animals, however, we observed when part of the metabolically produced $\mathrm{CO}_{2}$ 
was removed by the membrane lung that the ventilation of the animals proportionally decreased to maintain a constant blood partial pressure of $\mathrm{CO}_{2}[5]$. Artificial $\mathrm{CO}_{2}$ removal could therefore be a powerful and valuable tool to control the respiratory drive up to complete apnea [6]. Indeed, the focus of extracorporeal support was shifted from oxygenation to $\mathrm{CO}_{2}$ removal, aiming to provide lung rest to allow better healing. The hypothesis of limiting potential harmful stimuli was based uniquely on common sense, however, since concepts such as baby lung [7], atelectrauma [8], and so forth, were still unknown.

The first applications in humans of the concept of lung rest were reported in 1980 [9]. Soon after this experience a larger series of patients treated with extracorporeal $\mathrm{CO}_{2}$ removal and low-frequency positive-pressure ventilation was described by the same authors [10]. However, a small randomized trial conducted in the United States at the beginning of the 1990s failed to show an outcome advantage of additional extracorporeal support as compared with conventional mechanical ventilatory support [11]. Despite this lack of evidence, a few centers around Europe continued to provide veno-venous extracorporeal support in selected series of patients, usually as a last resort [12]. In contrast, in the United States Bartlett and colleagues continued to provide extracorporeal support with standard mechanical ventilation, with more liberal indications and with encouraging results $[13,14]$.

A renewed interest in this technique arose after the publication of the CESAR trial, which clearly showed an improvement in the death rate and severe disability 6 months after randomization, when patients with severe respiratory failure were treated with extracorporeal support in an expert high-case-volume center compared with nonspecialized hospital care [1]. Moreover, although not the primary outcome, an actual difference in survival of around $25 \%$ was observed for patients considered for ECMO treatment at 28 days, the primary outcome of most ARDS literature. However, the final explosion of the application of this extracorporeal support was due to the use of ECMO as a rescue therapy in Australia and New Zealand during the H1N1 influenza pandemic [15]. This increased use is also probably due to several technical improvements, which allowed a simpler and safer use of the technique. Among these innovations we can mention the introduction of nonporous hollow fiber devices, characterized by low resistance to blood flow, and polymethylpentene fibers that, combined with nonthrombogenic coatings, decrease the need for platelet transfusion and continuous heparin infusion. Moreover, recently introduced wire-reinforced walls of vascular access devices allow very thin cannula walls, reducing resistance to blood flow.

As the acronym ECMO includes several techniques with different aims, a brief reminder of the artificial lung's physiology is indicated to fully understand the different approaches, before discussing the latest reports on the topic.

\section{Physiology of the artificial lung Oxygenation}

The amount of oxygen provided via artificial lung is a direct function of the blood flow. The blood flow required during veno-venous bypass to achieve acceptable arterial oxygenation is usually between 3 and $61 /$ minute, partially depending on the cardiac output of the patient, on the hemoglobin concentration and on saturation. Of note, the gas flow required to fully oxygenate the incoming blood through the artificial lung may be quite low. For example, if we consider an entering hemoglobin saturation of $60 \%$ (with $3 \mathrm{l} /$ minute extracorporeal blood flow, $10 \mathrm{~g} / \mathrm{dl}$ hemoglobin concentration, $40 \mathrm{mmHg}$ partial pressure of oxygen in venous blood and approximately $85 \mathrm{ml} / \mathrm{l}$ oxygen content), to reach $100 \%$ saturation we would need $200 \mathrm{ml} /$ minute oxygen. Providing $0.2 \mathrm{l} /$ minute pure oxygen to a highly efficient membrane lung would therefore theoretically be sufficient. This underlines the fact that what is of primary importance for artificial oxygenation is the extracorporeal blood flow passing through the membrane lung, and not its ventilation.

The effects of the oxygen supplied by the membrane lung on systemic oxygenation depend on the type of cannulation and on the possible changes induced by the artificial oxygenation on the function of the native lung. In a veno-venous circuit the artificial lung is in series with the natural lung. The improvement in arterial oxygenation, in this case, is due to the increased oxygen saturation of the blood flowing through shunt regions of the natural lung. Great improvements from oxygenation can therefore not be expected. Moreover, with this type of vascular access, as blood with high oxygen saturation reaches the pulmonary artery, the shunt fraction of the natural lung usually increases due to the loss of hypoxic vasoconstriction [16]. Despite this, the veno-venous approach with high flow, even with very high shunt in the natural lung, provides vital arterial oxygenation.

The veno-arterial approach, mostly used for cardiac support, implies the drainage of venous blood, its oxygenation and the subsequent input in the arterial tree through a cannulated artery. The improvement of systemic oxygenation with this technique is much better as compared with the veno-venous approach because the artificially oxygenated blood mixes with arterial blood and directly perfuses distal organs. Moreover, in this type of cannulation - the artificial lung being in parallel with the natural lung - there is no loss of hypoxic vasoconstriction, because no highly oxygenated blood enters the pulmonary artery. Despite the unique ability to also provide cardiac support, this type of cannulation is 
characterized by major disadvantages. First, an artery typically the femoral artery - has to be cannulated with a large vascular catheter. This greatly increases the risk of ischemia of the inferior limb. Moreover, the aim of extracorporeal oxygenation (that is, to provide adequate oxygen supply to vital organs such as the brain and the heart) cannot be guaranteed through veno-arterial support if the input of oxygenated blood is performed distal to the great vessels; that is, through the femoral artery [16].

\section{Carbon dioxide removal}

The removal of $\mathrm{CO}_{2}$ is primarily a function of the flow of fresh gas. Theoretically it is possible to remove all of the metabolically produced $\mathrm{CO}_{2}$ (rate of elimination of $\mathrm{CO}_{2}$ about 200 to $250 \mathrm{ml} /$ minute) from 0.5 to $1 \mathrm{l} /$ minute venous blood due to its high $\mathrm{CO}_{2}$ content $(1 \mathrm{l}$ of venous blood at partial pressure of $\mathrm{CO}_{2} 45 \mathrm{mmHg}$ and $\mathrm{pH} 7.38$, in standard conditions, contains about $500 \mathrm{ml} \mathrm{CO}_{2}$ ). In this regard, the local acidification of entering blood may further enhance $\mathrm{CO}_{2}$ removal [17]. In the artificial lung, therefore, while high extracorporeal blood flow is required and low gas flow is sufficient for oxygenation, for $\mathrm{CO}_{2}$ removal very low extracorporeal blood flow is sufficient and high gas flow is required.

The extracorporeal $\mathrm{CO}_{2}$ removal allows the lungs to be put to rest, abolishing totally or partially the need for ventilation [18]. Indeed, if the main purpose of the application of the artificial lung is to allow lung rest and a gentle ventilation of the baby lung, low extracorporeal blood flows are sufficient [19]. In general, lower blood flow is feasible with smaller endovascular catheters and is associated with lower technical difficulties and complications. The approach of arterio-venous bypass with a pumpless device allows consistent $\mathrm{CO}_{2}$ removal at the price of an arterio-venous fistula [20-22]. Low-flow $\mathrm{CO}_{2}$ removal systems coupled to or uncoupled from hemofiltration may remove 20 to $30 \%$ of the rate of metabolically produced $\mathrm{CO}_{2}$ [23-26]. With artificial lungs actually available, total $\mathrm{CO}_{2}$ clearance requires a blood flow in the order of 1 to $2 \mathrm{l} /$ minute. Moreover, it is conceivable and desirable that, in the near future, regional anticoagulation (for example, with sodium citrate) will be available and will therefore greatly reduce the risk for bleeding due to systemic heparin infusion [27].

\section{The H1N1 flu pandemic}

The rebirth of extracorporeal respiratory support is primarily due to its use as a rescue therapy for lifethreatening hypoxemia in Australia and New Zealand during the H1N1 flu pandemic [15]. The proper choice for such a purpose was therefore a veno-venous bypass with large-bore drainage catheters to allow high blood flows. The overall survival rate in this selected population was higher than $70 \%$. After this report and in light of results from the CESAR trial [1], an impressive number of centers started to use this technique despite some scientists having expressed some doubt on the scientific evidence of its outcome advantages. The only evidence that led to the application of ECMO was the presence of moribund, severely hypoxemic patients that did not benefit from maximal mechanical ventilatory support [28-32]. Interestingly this technique was applied in Europe, the United States, South America, Canada and Asia, spreading as the H1N1 pandemic [33-38]. More than 1,000 papers were published from 2009 to May 2011; however, most articles were not related to the use of ECMO in H1N1 flu but referred for other indications, such as lung hyperinflation, cardiac failure or severe respiratory failure not caused by H1N1.

Extracorporeal support is a tool to buy time, maintaining life while awaiting improvement of the underlying disease. Therefore, it is theoretically crucial to take advantage of the extracorporeal support to minimize or, even better, to abolish the possible harm caused by an injurious mechanical ventilation. Extracorporeal $\mathrm{CO}_{2}$ removal, in fact, partially or totally abolishes the need for ventilation, allowing one to apply a gentle ventilatory approach. It would therefore be interesting to know how mechanical ventilation was performed during extracorporeal support in the latest published studies. Surprisingly, however, the details on settings of mechanical ventilators are difficult to retrieve because when some mention of mechanical ventilation is made the information is limited to a general agreement with ARDS Network suggestions [39]. Some papers specified more details, which are still in line with lung-protective strategies aiming for a further reduction of tidal volume (for example, 3 to $5 \mathrm{ml} / \mathrm{kg}$ ideal body weight) while maintaining relative high mean airway pressure by high positive end-expiratory pressure (PEEP). In this scenario, however, we may find extreme differences [15,36,40-42]. As an example, in several centers in Italy it was not uncommon to observe very low tidal volumes with the respiratory rate limited to 7 or 8 breaths/minute and a high mean airway pressure related to high PEEP application. On the other hand, in other units - for example at the Karolinska Institute of Stockholm - the patients are kept awake with $5 \mathrm{cmH}_{2} \mathrm{O}$ PEEP and ventilated with pressure support of 20 to $25 \mathrm{cmH}_{2} \mathrm{O}$ (personal communication, Dr Palmér, Section Manager of the ECMO Center, Karolinska Institute, Stockholm, Sweden). In our ICU in Milan, patients were treated initially with high PEEP, above $15 \mathrm{cmH}_{2} \mathrm{O}$, and lowfrequency ventilation [34]. To date, however, it is impossible to claim the superiority of a given treatment of the native lung during extracorporeal respiratory support as no studies are available on the topic. This lack of studies is primarily due to the scarcity of the patient 
population. However, it is important to emphasize - at least with regard to $\mathrm{H} 1 \mathrm{~N} 1$ patients - that the survival rate ranged from 56 to $79 \%$ throughout the centers, independent of the applied strategy of mechanical ventilation $[15,33,34,36]$.

We may therefore ask ourselves what we learned after this impressive utilization of extracorporeal support. First, extensive use of this technique all over the world in H1N1 patients confirmed that extracorporeal support is associated with high survival rates in severe hypoxemic patients. Moreover, we learned that these moribund patients may start time-buying extracorporeal respiratory support in the hospital of origin and thereafter be safely transferred to the referral ECMO centers. This practice has been clearly documented in Scandinavia $[42,43]$ as well as in Italy [44].

\section{Indications}

\section{Acute respiratory distress syndrome}

After these considerations we may now discuss the actual indications for ECMO. The choice of the technique, which may vary from low-flow bypass with $\mathrm{CO}_{2}$ removal to highflow ECMO with total oxygenation support, depends on the patient's situation and the physician's preference.

\section{Extracorporeal assistance as a rescue therapy}

If the aim is the treatment of life-threatening hypoxemia, the clear-cut indication is high-flow veno-venous ECMO. If the patient presents with severe cardiac failure, however, veno-arterial ECMO must be used. The obvious question is whether these types of treatment are associated with a better outcome.

The recently published CESAR trial provided some clues in this regard [1]. Many physicians, however, were not fully convinced by the investigators' approach [4547]. In fact, this pragmatic study really tested the differences in outcome between a specialized center with high-volume activity and single centers with low-volume activity. Despite these limitations the study strongly indicated that treatment with extracorporeal support may increase the survival rate in a selected population of patients with ARDS. We may ask ourselves why, after over 30 years, a classical, adequately powered randomized trial has not been conducted in these severely hypoxemic patients. To test a possible mortality difference of $10 \%$ between the ECMO and control arms would require enrollment of about 1,000 patients (with $90 \%$ power using a cutoff value for statistical significance of 0.05). Given that the enrollment rate of previous large randomized trials on severe ARDS [48-51] was approximately 0.3 patients/unit/month and that only one-third of these patients could have met the criteria for ECMO application - that is, severe refractory hypoxemia (partial pressure of oxygen $<100 \mathrm{mmHg}$ despite 100\%
$\mathrm{FiO}_{2}$ ) [52] - 20 ECMO centers would take over 40 years to complete the study (the CESAR trial took about 8 years). It therefore seems to us that a classical randomized trial is not feasible.

Despite this, there seems a high likelihood that extracorporeal support has saved the lives of some extremely severe patients. ECMO seems to be indicated in this type of patient because the risks from complications of the technique seem irrelevant when almost certain death can be predicted. The question is different when severe hypoxemia is still manageable with more conventional approaches (high PEEP, high-frequency oscillatory ventilation, $100 \% \mathrm{FiO}_{2}$, nitric oxide, and so forth). In these patients, the possible benefits of extracorporeal support have to be balanced with the only lethal complication of ECMO, which is intracranial hemorrhage. Unfortunately there are few data to predict with reasonable confidence the incidence of intracranial hemorrhage in adults [53]. According to the Italian ECMOnet experience, intracranial hemorrhage occurred in one patient out of 49 (personal communication, Dr Patroniti, San Gerardo Hospital, Monza, Italy). In our experience, however, the incidence was about $5 \%$ and this complication occurred both in subjects treated for hematologic malignancy and in patients with no predictable cause of increased bleeding susceptibility. Any time we consider a patient for ECMO we must therefore keep in mind this unpredictable and lethal complication.

\section{Extracorporeal assistance to provide lung rest}

If the aim of applying the artificial lung is not to assure oxygenation during hypoxemic emergency but to assure complete lung rest or to allow a protective lung strategy, $\mathrm{CO}_{2}$ removal is indicated. A technique that solely removes $\mathrm{CO}_{2}$ is applied in arterio-venous bypass [22]. With this technique the extracorporeal blood flow is low and oxygen transfer negligible, the input blood in the oxygenator being arterial and therefore already highly saturated. In our opinion, however, in ARDS patients it is safe to remove $\mathrm{CO}_{2}$ using devices that also allow the performance of blood flows up to 2 to $2.5 \mathrm{l} /$ minute. In this way, if needed, not only may lung rest be provided but also oxygenation maintained, in case of natural lung function deterioration.

\section{Extracorporeal assistance for indications other than ARDS}

Increased confidence in using extracorporeal assistance led to use of the technique in different clinical conditions. Although outside the aim of the present review, the following conditions should be noted.

\section{Bridge to lung transplant}

Extracorporeal assistance has been successfully used as a bridge to lung transplant in patients with terminal 
chronic obstructive pulmonary disease or cystic fibrosis. Of note, there is an increased tendency to maintain those patients awake, and spontaneously breathing, without the need for intubation [54].

\section{Lung hyperinflation}

Lung hyperinflation is common during chronic obstructive pulmonary disease exacerbation or during status asthmaticus. In this condition, when noninvasive mechanical ventilation fails, extracorporeal support may be applied. The primary aim is to remove $\mathrm{CO}_{2}$, therefore reducing spontaneous ventilation and allowing progressive lung deflation [55].

\section{Cardiac failure}

There is much experience providing extracorporeal assistance during cardiogenic shock. In this condition the approach is obviously venous-arterial, providing not only respiratory but also cardiac assistance.

\section{Conclusion}

Recent events moved the spots of scientific interest once again on extracorporeal techniques of respiratory support. Since the first experiences with ECMO, technology has hugely evolved, making extracorporeal respiratory support safer and more cost-effective. Indeed, extracorporeal respiratory support is now an attractive strategy for the treatment of any type of respiratory failure in addition to, or even as an alternative to, mechanical ventilation.

\section{Abbreviations}

ARDS, acute respiratory distress syndrome; $\mathrm{CO}_{2}$, carbon dioxide; $\mathrm{ECMO}$, extracorporeal membrane oxygenation; $\mathrm{FiO}_{2}$, inspired oxygen fraction; PEEP, positive end-expiratory pressure.

\section{Competing interests}

The authors declare that they have no competing interests.

\section{Author details}

'Dipartimento di Anestesia, Rianimazione (Intensiva e Subintensiva) e Terapia del Dolore, Fondazione IRCCS Ca'Granda, Ospedale Maggiore Policlinico, Via Francesco Sforza 35, 20122 Milan, Italy. ²Dipartimento di Anestesiologia, Terapia Intensiva e Scienze Dermatologiche, Fondazione IRCCS Ca' Granda Ospedale Maggiore Policlinico di Milano, Università degli Studi, Via Francesco Sforza 35, 20122 Milano, Italy.

Published: 8 December 2011

\section{References}

1. Peek GJ, Mugford M, Tiruvoipati R, Wilson A, Allen E, Thalanany MM, Hibbert CL, Truesdale A, Clemens F, Cooper N, Firmin RK, Elbourne D: Efficacy and economic assessment of conventional ventilatory support versus extracorporeal membrane oxygenation for severe adult respiratory failure (CESAR): a multicentre randomised controlled trial. Lancet 2009, 374:1351-1363.

2. Hill JD, O'Brien TG, Murray JJ, Dontigny L, Bramson ML, Osborn JJ, Gerbode F: Prolonged extracorporeal oxygenation for acute post-traumatic respiratory failure (shock-lung syndrome). Use of the Bramson membrane lung. N Engl J Med 1972, 286:629-634.

3. Bartlett RH, Gazzaniga AB, Jefferies MR, Huxtable RF, Haiduc NJ, Fong SW: Extracorporeal membrane oxygenation (ECMO) cardiopulmonary support in infancy. Trans Am Soc Artif Intern Organs 1976, 22:80-93.
4. Zapol WM, Snider MT, Hill JD, Fallat RJ, Bartlett RH, Edmunds LH, Morris AH, Peirce EC, Thomas AN, Proctor HJ, Drinker PA, Pratt PC, Bagniewski A, Miller $\mathrm{RG} J \mathrm{~J}$ : Extracorporeal membrane oxygenation in severe acute respiratory failure. A randomized prospective study. JAMA 1979, 242:2193-2196.

5. Kolobow T, Gattinoni L, Tomlinson T, White D, Pierce J, lapichino G: The carbon dioxide membrane lung (CDML): a new concept. Trans Am Soc Artif Intern Organs 1977, 23:17-21.

6. Kolobow T, Gattinoni L, Tomlinson TA, Pierce JE: Control of breathing using an extracorporeal membrane lung. Anesthesiology 1977, 46:138-141.

7. Gattinoni L, Pesenti A: The concept of 'baby lung'. Intensive Care Med 2005, 31:776-784.

8. Muscedere JG, Mullen JB, Gan K, Slutsky AS: Tidal ventilation at low airway pressures can augment lung injury. Am J Respir Crit Care Med 1994, 149:1327-1334.

9. Gattinoni L, Agostoni A, Pesenti A, Pelizzola A, Rossi GP, Langer M, Vesconi S, Uziel L, Fox U, Longoni F, Kolobow T, Damia G: Treatment of acute respiratory failure with low-frequency positive-pressure ventilation and extracorporeal removal of $\mathrm{CO}_{2}$. Lancet 1980, 2:292-294.

10. Gattinoni L, Pesenti A, Mascheroni D, Marcolin R, Fumagalli R, Rossi F, lapichino G, Romagnoli G, Uziel L, Agostoni A: Low-frequency positivepressure ventilation with extracorporeal $\mathrm{CO}_{2}$ removal in severe acute respiratory failure. JAMA 1986, 256:881-886.

11. Morris AH, Wallace CJ, Menlove RL, Clemmer TP, Orme JF, Jr., Weaver LK, Dean NC, Thomas F, East TD, Pace NL, Suchyta MR, Beck E, Bombino M, Sittig DF, Bohm S, Hoffmann B, Becks H, Butler S, Pearl J, Rasmusson B: Randomized clinical trial of pressure-controlled inverse ratio ventilation and extracorporeal $\mathrm{CO}_{2}$ removal for adult respiratory distress syndrome. Am J Respir Crit Care Med 1994, 149:295-305.

12. Lewandowski K, Rossaint R, Pappert D, Gerlach H, Slama KJ, Weidemann H, Frey DJ, Hoffmann O, Keske U, Falke KJ: High survival rate in 122 ARDS patients managed according to a clinical algorithm including extracorporeal membrane oxygenation. Intensive Care Med 1997, 23:819-835.

13. Kolla S, Awad SS, Rich PB, Schreiner RJ, Hirschl RB, Bartlett RH: Extracorporeal life support for 100 adult patients with severe respiratory failure. Ann Surg 1997, 226:544-564

14. Bartlett RH, Roloff DW, Custer JR, Younger JG, Hirschl RB: Extracorporeal life support: the University of Michigan experience. JAMA 2000, 283:904-908.

15. Davies A, Jones D, Bailey M, Beca J, Bellomo R, Blackwell N, Forrest P, Gattas D, Granger E, Herkes R, Jackson A, McGuinness S, Nair P, Pellegrino V, Pettila V, Plunkett B, Pye R, Torzillo P, Webb S, Wilson M, Ziegenfuss M: Extracorporeal membrane oxygenation for 2009 influenza $A(\mathrm{H} 1 \mathrm{~N} 1)$ acute respiratory distress syndrome. JAMA 2009, 302:1888-1895.

16. Lamy M, Eberhart RC, Fallat RJ, Dietrich HP, Ratliff J, Hill JD: Effects of extracorporeal membrane oxygenation (ECMO) on pulmonary hemodynamics, gas exchange and prognose. Trans Am Soc Artif Intern Organs 1975, 21:188-198.

17. Zanella A, Patroniti N, Isgro S, Albertini M, Costanzi M, Pirrone F, Scaravilli V, Vergnano B, Pesenti A: Blood acidification enhances carbon dioxide removal of membrane lung: an experimental study. Intensive Care Med 2009, 35:1484-1487.

18. Kolobow T, Gattinoni L, Tomlinson T, Pierce JE: An alternative to breathing. J Thorac Cardiovasc Surg 1978, 75:261-266.

19. Brunet F, Mira JP, Dhainaut JF, Dall'ava-Santucci J: Efficacy of low-frequency positive-pressure ventilation-extracorporeal $\mathrm{CO}_{2}$ removal. Am J Respir Crit Care Med 1995, 151:1269-1270.

20. Ohtake S, Kawashima Y, Hirose H, Matsuda H, Nakano S, Kaku K, Okuda A: Experimental evaluation of pumpless arteriovenous ECMO with polypropylene hollow fiber membrane oxygenator for partial respiratory support. Trans Am Soc Artif Intern Organs 1983, 29:237-241.

21. Bein T, Scherer MN, Philipp A, Weber F, Woertgen C: Pumpless extracorporeal lung assist ( $p E C L A)$ in patients with acute respiratory distress syndrome and severe brain injury. J Trauma 2005, 58:1294-1297.

22. Bein T, Weber F, Philipp A, Prasser C, Pfeifer M, Schmid FX, Butz B, Birnbaum D, Taeger K, Schlitt HJ: A new pumpless extracorporeal interventional lung assist in critical hypoxemia/hypercapnia. Crit Care Med 2006, 34:1372-1377.

23. Terragni PP, Del Sorbo L, Mascia L, Urbino R, Martin EL, Birocco A, Faggiano C, Quintel M, Gattinoni L, Ranieri VM: Tidal volume lower than $6 \mathrm{ml} / \mathrm{kg}$ enhances lung protection: role of extracorporeal carbon dioxide removal. Anesthesiology 2009, 111:826-835.

24. Livigni S, Maio M, Ferretti E, Longobardo A, Potenza R, Rivalta L, Selvaggi P, 
Vergano M, Bertolini G: Efficacy and safety of a low-flow veno-venous carbon dioxide removal device: results of an experimental study in adult sheep. Crit Care 2006, 10:R151.

25. Ruberto F, Pugliese F, D'Alio A, Perrella S, D'Auria B, lanni S, Anile M, Venuta F, Coloni GF, Pietropaoli P: Extracorporeal removal $\mathrm{CO}_{2}$ using a venovenous, low-flow system (Decapsmart) in a lung transplanted patient: a case report. Transplant Proc 2009, 41:1412-1414.

26. Batchinsky Al, Jordan BS, Regn D, Necsoiu C, Federspiel WJ, Morris MJ, Cancio LC: Respiratory dialysis: reduction in dependence on mechanical ventilation by venovenous extracorporeal $\mathrm{CO}_{2}$ removal. Crit Care Med 2011, 39:1382-1387.

27. Cardenas VJ, Jr, Miller L, Lynch JE, Anderson MJ, Zwischenberger JB: Percutaneous venovenous $\mathrm{CO}_{2}$ removal with regional anticoagulation in an ovine model. ASAIO J 2006, 52:467-470.

28. Mitchell MD, Mikkelsen ME, Umscheid CA, Lee I, Fuchs BD, Halpern SD: A systematic review to inform institutional decisions about the use of extracorporeal membrane oxygenation during the $\mathrm{H} 1 \mathrm{~N} 1$ influenza pandemic. Crit Care Med 2010, 38:1398-1404.

29. Park PK, Dalton HJ, Bartlett RH: Point: Efficacy of extracorporeal membrane oxygenation in 2009 influenza A(H1N1): sufficient evidence? Chest 2010, 138:776-778.

30. Morris AH, Hirshberg E, Miller RR, III, Statler KD, Hite RD: Counterpoint: Efficacy of extracorporeal membrane oxygenation in 2009 influenza A(H1N1): sufficient evidence? Chest 2010, 138:778-781.

31. MacLaren G: Evidence and experience in extracorporeal membrane oxygenation. Chest 2011, 139:965-966.

32. Hubmayr RD, Farmer JC: Should we'rescue' patients with 2009 influenza $\mathrm{A}(\mathrm{H} 1 \mathrm{~N} 1)$ and lung injury from conventional mechanical ventilation? Chest 2010, 137:745-747.

33. Roch A, Lepaul-Ercole R, Grisoli D, Bessereau J, Brissy O, Castanier M, Dizier S, Forel JM, Guervilly C, Gariboldi V, Collart F, Michelet P, Perrin G, Charrel R, Papazian L: Extracorporeal membrane oxygenation for severe influenza $A$ (H1N1) acute respiratory distress syndrome: a prospective observational comparative study. Intensive Care Med 2010, 36:1899-1905.

34. Norfolk SG, Hollingsworth CL, Wolfe CR, Govert JA, Que LG, Cheifetz IM, Hollingsworth JW: Rescue therapy in adult and pediatric patients with pH1N1 influenza infection: a tertiary center intensive care unit experience from April to October 2009. Crit Care Med 2010, 38:2103-2107.

35. Ugarte S, Arancibia F, Soto R: Influenza A pandemics: clinical and organizational aspects: the experience in Chile. Crit Care Med 2010, 38:e133-e137.

36. Freed DH, Henzler D, White CW, Fowler R, Zarychanski R, Hutchison J, Arora RC, Manji RA, Legare JF, Drews T, Veroukis S, Kesselman M, Guerguerian AM, Kumar A: Extracorporeal lung support for patients who had severe respiratory failure secondary to influenza A (H1N1) 2009 infection in Canada. Can J Anaesth 2010, 57:240-247.

37. Kao TM, Wu UI, Chen YC: Rapid diagnostic tests and severity of illness in pandemic (H1N1) 2009, Taiwan. Emerg Infect Dis 2010, 16:1181-1183.

38. Liong T, Lee KL, Poon YS, Lam SY, Chan CP, Yue CS, Chu CM, Yuen KY, Law KI: The first novel influenza A (H1N1) fatality despite antiviral treatment and extracorporeal membrane oxygenation in Hong Kong. Hong Kong Med J 2009, 15:381-384.

39. Ventilation with lower tidal volumes as compared with traditional tidal volumes for acute lung injury and the acute respiratory distress syndrome. The Acute Respiratory Distress Syndrome Network. N Engl J Med 2000, 342:1301-1308.

40. Cianchi G, Bonizzoli M, Pasquini A, Bonacchi M, Zagli G, Ciapetti M, Sani G, Batacchi S, Biondi S, Bernardo P, Lazzeri C, Giovannini V, Azzi A, Abbate R, Gensini G, Peris A: Ventilatory and ECMO treatment of H1N1-induced severe respiratory failure: results of an Italian referral ECMO center. BMC Pulm Med 2011, 11:2

41. Dominguez-Cherit G, Lapinsky SE, Macias AE, Pinto R, Espinosa-Perez L, de la TA, Poblano-Morales M, Baltazar-Torres JA, Bautista E, Martinez A, Martinez
MA, Rivero E, Valdez R, Ruiz-Palacios G, Hernandez M, Stewart TE, Fowler RA: Critically ill patients with 2009 influenza A(H1N1) in Mexico. JAMA 2009, 302:1880-1887.

42. Holzgraefe B, Broome M, Kalzen H, Konrad D, Palmer K, Frenckner B: Extracorporeal membrane oxygenation for pandemic H1N1 2009 respiratory failure. Minerva Anestesiol 2010, 76:1043-1051.

43. Linden V, Palmer K, Reinhard J, Westman R, Ehren H, Granholm T, Frenckner B: Inter-hospital transportation of patients with severe acute respiratory failure on extracorporeal membrane oxygenation - national and international experience. Intensive Care Med 2001, 27:1643-1648.

44. Patroniti N, Zangrillo A, Pappalardo F, Peris A, Cianchi G, Braschi A, lotti GA, Arcadipane A, Panarello G, Ranieri VM, Terragni P, Antonelli M, Gattinoni L, Oleari F, Pesenti A: The Italian ECMO network experience during the 2009 influenza $\mathrm{A}(\mathrm{H} 1 \mathrm{~N} 1)$ pandemic: preparation for severe respiratory emergency outbreaks. Intensive Care Med 2011, 37:1447-1457.

45. Zwischenberger JB, Lynch JE: Will CESAR answer the adult ECMO debate? Lancet 2009, 374:1307-1308.

46. Wallace DJ, Milbrandt EB, Boujoukos A: Ave, CESAR, morituri te salutant! (Hail, CESAR, those who are about to die salute you!). Crit Care 2010, 14:308.

47. Brindley $P G$, Cave $D$, Lequier $L$ : BEST evidence in critical care medicine. Extracorporeal membrane oxygenation (ECMO) in severe adult respiratory distress syndrome. Can J Anaesth 2010, 57:273-275.

48. Gattinoni L, Tognoni G, Pesenti A, Taccone P, Mascheroni D, Labarta V, Malacrida R, Di Giulio P, Fumagalli R, Pelosi P, Brazzi L, Latini R: Effect of prone positioning on the survival of patients with acute respiratory failure. $N$ Engl J Med 2001, 345:568-573.

49. Guerin C, Gaillard S, Lemasson S, Ayzac L, Girard R, Beuret P, Palmier B, Le QV, Sirodot M, Rosselli S, Cadiergue V, Sainty JM, Barbe P, Combourieu E, Debatty D, Rouffineau J, Ezingeard E, Millet O, Guelon D, Rodriguez L, Martin O, Renault A, Sibille JP, Kaidomar M: Effects of systematic prone positioning in hypoxemic acute respiratory failure: a randomized controlled trial. JAMA 2004, 292:2379-2387.

50. Mancebo J, Fernandez R, Blanch L, Rialp G, Gordo F, Ferrer M, Rodriguez F, Garro P, Ricart P, Vallverdu I, Gich I, Castano J, Saura P, Dominguez G, Bonet A, Albert RK: A multicenter trial of prolonged prone ventilation in severe acute respiratory distress syndrome. Am J Respir Crit Care Med 2006, 173:1233-1239.

51. Taccone P, Pesenti A, Latini R, Polli F, Vagginelli F, Mietto C, Caspani L, Raimondi F, Bordone G, lapichino G, Mancebo J, Guerin C, Ayzac L, Blanch L, Fumagalli R, Tognoni G, Gattinoni L: Prone positioning in patients with moderate and severe acute respiratory distress syndrome: a randomized controlled trial. JAMA 2009, 302:1977-1984.

52. Bernard GR, Artigas A, Brigham KL, Carlet J, Falke K, Hudson L, Lamy M, LeGal $J R$, Morris A, Spragg R: The American-European Consensus Conference on ARDS. Definitions, mechanisms, relevant outcomes, and clinical trial coordination. Am J Respir Crit Care Med 1994, 149:818-824.

53. Kasirajan V, Smedira NG, McCarthy JF, Casselman F, Boparai N, McCarthy PM: Risk factors for intracranial hemorrhage in adults on extracorporeal membrane oxygenation. Eur J Cardiothorac Surg 1999, 15:508-514.

54. Olsson KM, Simon A, Strueber M, Hadem J, Wiesner O, Gottlieb J, Fuehner T, Fischer S, Warnecke G, Kuhn C, Haverich A, Welte T, Hoeper MM: Extracorporeal membrane oxygenation in nonintubated patients as bridge to lung transplantation. Am J Transplant 2010, 10:2173-2178.

55. Crotti S, Lissoni A, Tubiolo D, Azzari S, Tarsia P, Caspani ML, Gattinoni L: Artificial lung as an alternative to mechanical ventilation in COPD exacerbation. Eur Resp J 2012, 39:in press.

\section{doi:10.1186/cc10490}

Cite this article as: Gattinoni L, et al:: Clinical review: Extracorporeal membrane oxygenation. Critical Care 2011, 15:243. 